\title{
IMMUNOLOGICAL RESPONSE OF A NEW TRIVALENT CAPRIPOX- VIRUS VACCINE IN PREGNANT EWES AND DOES
}

\author{
Eman B. Abd-Elfatah ${ }^{1}$, Mamdouh F. El-Mekkawi ${ }^{1}$, Emad A. Aboul-Soud², \\ Elshaima M. Fawzi ${ }^{1 *}$, Sherif A. El-Soally ${ }^{3}$
}

${ }^{1}$ Department of Animal Medicine, Division of Infectious Diseases, Faculty of Veterinary Medicine, Zagazig University, Sharkia , 44511, Egypt, ${ }^{2}$ Veterinary Serum and Vaccines Research Institute, Department of Pox, Abbasia, Cairo, Egypt, ${ }^{3}$ Military Veterinary Hospital, Cairo, Egypt

*Corresponding author, E-mail: elshaimafawzi@yahoo.es, a.fawzy@zu.edu.eg

\begin{abstract}
This study was conducted as a field trial of using a new candidate trivalent Capripoxvirus (CaPVs) vaccine in pregnant ewes and does to detect safety degree and level of immunity, in comparison with commercial Romanian sheep pox viral (RSPPV) vaccine. Monitoring the post-vaccinal reaction and measurement of cellular and humoral immunity by evaluating the lymphocyte proliferation assay (LPA) and serum neutralization test (SNT), respectively, in addition to detect the acquired maternal immunity in new-born lambs and kids. The post-vaccine reaction in animals vaccinated with trivalent CaPVs vaccine was more noticeable than that vaccinated with RSPPV vaccine without significant difference (P-Value>0.05). In vitro, the evaluation of cellular and humoral immunity revealed that the animals vaccinated with trivalent vaccine can significantly induce lymphocyte proliferation response in addition to of high level of antibodies (Abs) in comparison to that vaccinated with RSPPV vaccine ( $P$-Value $<0.05$ ) with peak titre of lymphocyte proliferation and Abs titre at $10^{\text {th }}$ and $28^{\text {th }}$, respectively. Furthermore, the evaluation of maternal immunity in new-born lambs and kids from previously vaccinated dams with trivalent CaPVs and RSPPV vaccines by SNT was shown that the peak level of receiving immunity was appeared at 1st week after birth with increasing its level in lambs and kids of dams vaccinated with trivalent CaPVs vaccine than those of dams vaccinated with RSPPV vaccine with a significant difference in between ( $P$-Value $<0.05)$. The result of this study provide a good profile about a high immune response with a long level of maternal immunity provided with trivalent CaPVs vaccine in comparison to the RSPPV vaccine so toward about the preferable use of new vaccine to control infection with sheep and goat pox diseases. Trivalent CaPVs vaccine could be candidate to be used against lumpy skin disease (LSD) due to antigenic relationship between genus CaPVs strains.
\end{abstract}

Key words: does; ewes; monovalent RSPPV; safety; trivalent CaPVs

\section{Introduction}

Sheep and goat pox (SGP) diseases are one of the contagious viral diseases affecting small ruminants caused by sheep pox virus (SPPV) and goat pox virus (GTPV), belonged to genus Capripoxvirus (CaPVs) along with lumpy skin disease virus (LSDV) of cattle, within family 
Poxviridae (1). CaPVs strains are antigenically and serologically identical but can be differentiated at the genetic level (2). In adequate management, bad hygiene and a route of CaPVs diseases transmission corroborate the diseases spreading particular in the poor farmers and this adversely affects on central economy that relay on the production of livestock (3).

SPPV and GTPV were considered to be host specific viruses but some strains as Yemen, Kenya and Oman isolates infect both goats and sheep while most SPPV and GTPV isolates show distinct host preferences with more virulence in one of the two species (1). Cross protection between SPPV and GTPV or vice versa is partial so a homologous vaccine was recommended for an optimum protection $(4,5)$. In the most countries at least two different vaccines containing the isolates of either GTPV or SPPV are necessary to protect small ruminants against both viruses $(6,7)$.

In endemic countries with CaPVs, control of the diseases depend mainly on a laboratory diagnosis that followed by a quarantine application, in addition to a vaccination is considered the most easy and effective protection way against all CaPVs diseases $(8,9,10)$. Live attenuated tissue culture vaccines in a lyophilized form provided a good protection and able to control an outbreaks of CaPVs diseases (11).

CaPVs strains share a major neutralizing site; consequently it is possible to protect cattle against LSD using strains of CaPVs derived from either sheep or goats as used in Egypt by using Romanian sheep pox (RSPPV) vaccine. Furthermore SPPV and GTPV do not occur in Southern Africa so only attenuated LSD vaccine are used, whereas in northern, central Africa and in the Middle East where the distribution of SPP, GTP and LSD viruses overlap, an attenuated SPP vaccines such KSGP O-240, RM65 and Romanian SPPV strains have been used against LSD (12,13).

Kenyan SGP O108 vaccine used to immunize both small ruminant and cattle against CaPVs with remarkable success $(11,14,15)$. In Egypt, it was reported that the live attenuated RSPPV vaccine did not provide cattle with complete protection against LSD and reoccurrence of an outbreaks in vaccinated animals (16-18), goats vaccinated with RSPPV vaccine are fully unsuccessful $(6,19)$.

In Egypt, three CaPVs (SPPV, GTPV, LSDV) were endemic and appeared in sporadic and an outbreak cases, trying to use a trivalent vaccine of SPPV strains (Romanian, Kenyan 0180) and GTPV vaccine with an equal volume and nearly equal titre used as abroad-spectrum vaccine candidates against all CaPVs diseases is a good trail with a remarkable high immunity compared with commercial RSPPV vaccine alone (20-22). SPPV and GTPV vaccines do not replicate in small animals models to evaluate its efficacy, an evaluation of the vaccine in its preferable and specific host is the first step to detect the efficacy of the vaccine experimentally and in field application.

This study was done to evaluate the safety and efficacy of trivalent CaPVs vaccine in pregnant animals by evaluating both cell-mediated immunity (CMI) and humoral immunity, in comparison with positive control group of vaccinated pregnant small ruminants with commercial RSPPV vaccine. In addition to evaluate the passive maternal immunity in new-born lambs and kids to determine the suitable time to start vaccination in both types of vaccines.

\section{Materials and methods}

The experimental protocol was approved by Zagazig University Institutional Animal Care and Use Committee (ZU-IACUC/2/F/98/2018)

\section{Animals}

Pregnant small ruminants (ewes, does)

Eighteen ewes and seventeen does at last third of pregnancy and free from antibodies (Abs) against SGPV in which 5 of these animals (3ewes and 2 does) were applied to check the safety test of new candidate trivalent CaPVs vaccine, other thirty ewes (15 ones) and does (15 ones) were divided into 3 groups: Group 1 (G1) composed of 12 ewes and does, divided equally, were vaccinated with trivalent vaccine; (G2) composed of 12 ewes and does, divided equally, were vaccinated with RSPPV vaccine 
(control positive) and (G3) composed of 6 unvaccinated animals (control negative).

New-born lambs and kids

Thirteen lambs and thirteen kids with good healthy, well-body condition and have adequate amount of colostrums directly after parturition were chosen in this experiment. The new-born lambs and kids were divided into 3 groups: (G4) 10 lambs and kids from dams vaccinated with trivalent vaccine, (G5) 10 lambs and kids from dams vaccinated with RSPPV vaccine (control positive), (G6) 6 from unvaccinated dams (control negative).

Vaccines and animals vaccination program

Experimentally trivalent vaccine composed of three strains (KSPP O108, RSSP and Held GTP) with a titer (10 4.75 TCID50) and monovalent RSPPV vaccine ( $10^{5.25}$ TCID 50) that was obtained kindly from the veterinary serum and vaccine research institute (VSVRI), Egypt. The titer of each virus vaccine was titrated according to Reed and Muench (23). Reconstituted vaccines with sterile phosphate-buffered saline were kept on ice, protected from direct sunlight and used within 1hour (h). Pregnant dams were vaccinated at last 2 months of pregnancy with 1 $\mathrm{ml}$ /intradermal or/and subcutaneous according to manufacture instructions of the reconstituted vaccines contain $\left(10^{2.5} \mathrm{TCID} 50 / \mathrm{ml}\right)$ according to the manufacturer's instructions, while the control group kept un-vaccinated.

\section{Safety test}

The new candidate trivalent CaPVs was tested to check its safety by inoculation 5 pregnant small ruminants ( 3 ewes and 2 does) with 20x field dose I/D (14).

\section{Samples}

Peripheral blood mononuclear cells (PBMCs)

Whole blood collected from both vaccinated and control animals regularly at $0,2,5,10,20$, 30 days post-vaccination from jugular vein, PBMCs separated by collection $3 \mathrm{ml}$ of peripheral blood from each animal on $\mathrm{Na}$ heparin, blood was overlaid on the surface of lymphocyte separation medium by lymph prep (1:1) in sterile centrifuge tubes then centrifuged at 2500 rpm for 30 minutes, PBMCs aspirated by pipette from interphase layer and washed 3 times by heparinized PBS after centrifuged at 2000 rpm for $10 \mathrm{~min}$ (24), cells re-suspended in RPMI-1640 with antibiotic and 10\% FCS.

\section{Serum}

Serum samples were collected from pregnant sheep and goats to monitoring the immune response Abs for 3 months at day 0 before vaccination then every week during $1^{\text {st }}$ month post vaccination then every 2 weeks during $2^{\text {nd }}$ and $3^{\text {rd }}$ months post vaccination $(0,1,2,3,4,6,8$, weeks...etc). Good healthy new-born lambs and kids were selected for assessment of maternal immunity which were clinically examined for well-weight and good general body condition, serum samples were collected weekly at $1^{\text {st }}$ month then every two weeks at $2^{\text {nd }}$ and at $3^{\text {rd }}$ months of age $(1,2,3,4,6,8$, weeks...etc), to determine the level maternal Abs against the two types of vaccines which transferred from vaccinated dams to their new-lambs and kids and the best time of immunization, all the serum samples were tested for the presence of Abs by using SNT.

\section{Lymphocyte proliferation assay (LPA)}

LPA was done in 96-well flat-bottom plates using XTT assay according to $(25,26)$, the assay was carried on PBMCs according to the instructions KitX6493 purchased from thermofisher scientific company, briefly PBMCs cells grown in a 96-well plate at a density of $10^{4}-10^{5}$ cells/well in $100 \mu \mathrm{L}$ of culture medium, the plate was incubated in a $\mathrm{CO}_{2}$ incubator for $24-48 \mathrm{~h}, 10 \mu \mathrm{L}$ of the prepared PMS solution in the prepared $4 \mathrm{~mL}$ of XTT solution created immediately before labeling cells, 25 $\mu \mathrm{L}$ of XTT/PMS solution directly to each well then the plate incubate for $2 \mathrm{~h}$ at $37^{\circ} \mathrm{C}$ in a $\mathrm{CO}_{2}$ incubator and read absorbance at $450 \mathrm{~nm}$.

\section{Serum neutralization test (SNT)}

The test was applied to detect Abs level before and after vaccination of pregnant ewes and does and passive maternal Abs in new- born 
lambs and kids to detect the best time to start vaccination. SNT was applied according to the standard protocol of VSVRI following the OIE manual (14), the neutralization index (NI) was calculated according to Reed and Muench (23).

\section{Statistical analysis}

In the present study, the obtained data was analyzed by two-way repeated measures ANOVA procedures of the Statistical Package for Social Sciences version 21.0 (SPSS for Windows 21.0, Inc, Chicago, IL, USA). Results were documented as means \pm standard error (SE), P-value $<0.05$ was used to indicate statistical significance and the difference among the means were determined by Duncan multiple range test (DMRT).

\section{Results}

Safety test and the post-vaccine reaction

The safety test of new trivalent CaPVs vaccines was checked before field administration of the vaccine, the vaccine was safe without abortion case recorded, after that the trivalent CaPVs vaccine was applied in the field trial in comparison with RSPPV. Both vaccinated groups (G1, G2) were put under a closed observation for 14 days to detect the post-vaccine reaction particularly measuring of rectal temperatures. Clinical examination reveal that there is no clinical signs of CaPVs infection were appeared except rise of temperature was observed in $\mathrm{G} 1$ after $24-72 \mathrm{~h}$ post- vaccination while in G2 slight rise of temperature was appeared after 48- $72 \mathrm{~h}$ post-vaccination (Table 1 ) without significant difference between both group (Pvalue $>0.05)$, this rise of temperature was accompanied by slight loss of appetite and slight increase of respiratory rate without any abortion. Moreover all animals were still in complete alert state with good body condition. Mild local reaction at the inoculation site in both vaccinated groups was appeared in the form of slight redness and swelling as shown in (Fig. 1) that disappeared within 4-5 days from vaccination.
Evaluation of cellular immunity by lymphocyte proliferation response

Lymphocyte response was calculated as optical density (O.D) by using sensitive XTT substance that varies from time to time and from animal to animal in each group. PBMCs of vaccinated groups were shown higher lymphocytes proliferation than un-vaccinated group with significant difference (P-value $<0.05)$. Mean lymphocytes proliferation of G1 (trivalent vaccinated group) were higher than G2 (monovalent vaccinated group) with significant difference (P-value $<0.05$ ) at all time of PBMCs samples collection, along the time of experiment O.D of lymphocytes proliferation in sheep was higher than goats in response to vaccines. Peak level of lymphocytes proliferation in both G1 and G2 was appeared at $10^{\text {th }}$ DPV then decreased thereafter (Fig. 2).

\section{Evaluation of humoral immunity by SNT}

Serum samples were collected to detect Abs titer using SNT in vaccinated and un-vaccinated groups, the mean protective neutralization index (NI) was detectable after $2^{\text {st }} \mathrm{WPV}$ in sheep and goat vaccinated with trivalent CaPVs vaccine $(1.750 \pm 0.102)$ then increased gradually till reached to the peak level at $4^{\text {th }}$ WPV with average means $(2.6250 \pm 0.143,2.1563 \pm 0.105)$ in G1 and G2 respectively with significant difference $(\mathrm{P}<0.05)$ in between. Sheep and goats in G1 were shown higher mean NI than sheep and goats in G2 with significant difference $(\mathrm{P}<0.05)$ between weeks of samples collection (Fig. 3).

\section{Evaluation of maternal immunity in new- born lambs and kids using SNT}

Peak protective $(\mathrm{NI}>1.5)$ was recorded at $1^{\text {st }}$ week in lambs and kids of G4 and G5 compared with non-protective NI in G6 with significant difference $(\mathrm{P}<0.05)$ between groups, average means of NI in each group differ between weeks of serum samples collection with significant difference $(\mathrm{P}<0.05)$. In $\mathrm{G} 4$ (lambs and kids from trivalent vaccinated dams) the level of NI of Abs remain till $10^{\text {th }}$ week after birth protective with a relatively high level in lambs and kids, on the other side Abs of lambs and 
kids from monovalent vaccinated dams (G5) results lambs were received higher level of Abs remain protective till $6^{\text {th }}$ and $4^{\text {th }}$ weeks after than kids.

birth respectively (Table 2 ). From the obtained

Table 1: Physical parameters of vaccinated groups

\begin{tabular}{|c|c|c|c|c|}
\hline \multirow{3}{*}{$\begin{array}{l}\text { *Days post } \\
\text { vaccination } \\
\text { (DPV) }\end{array}$} & \multicolumn{4}{|c|}{ Parameters } \\
\hline & \multicolumn{2}{|c|}{ Body temperature $\left({ }^{0} \mathrm{C}\right)$} & \multicolumn{2}{|c|}{ Habitus } \\
\hline & G1 & $\mathrm{G} 2$ & G1 & $\mathrm{G} 2$ \\
\hline 0 & $39.5 \pm 0.092$ & $39.48 \pm 0.037$ & Alert & Alert \\
\hline 1 & $39.74 \pm 0.302$ & $39.5 \pm 0.031$ & $\begin{array}{l}\text { Slight decrease in } \\
\text { appetite and animals } \\
\text { movement with } \\
\text { slightlyincreased } \\
\text { respiratory rate }\end{array}$ & $\begin{array}{l}\text { Slightly decrease of } \\
\text { animals movement } \\
\text { with good } \\
\text { respiratory rate }\end{array}$ \\
\hline 2 & $39.82 \pm 0.102$ & $39.64 \pm 0.051$ & $\begin{array}{l}\text { Slightly decrease in } \\
\text { appetite and animals } \\
\text { movement }\end{array}$ & $\begin{array}{l}\text { Mild decrease in } \\
\text { appetite }\end{array}$ \\
\hline 3 & $39.86 \pm 0.103$ & $39.64 \pm 0.024$ & $\begin{array}{c}\text { Animals appetite is } \\
\text { acceptable with good } \\
\text { movable }\end{array}$ & $\begin{array}{l}\text { Animals became } \\
\text { alert with good } \\
\text { movable }\end{array}$ \\
\hline 5 & $39.66 \pm 0.093$ & $39.5 \pm 0.032$ & Alert & Alert \\
\hline 7 & $39.62 \pm 0.073$ & $39.42 \pm 0.012$ & Alert & Alert \\
\hline 14 & $39.5 \pm 0.051$ & $39.4 \pm 0.03$ & Alert & Alert \\
\hline
\end{tabular}

*Significant difference $(\mathrm{P}-\mathrm{V}$ alue $<0.05)$ between days of post-vaccinal reaction
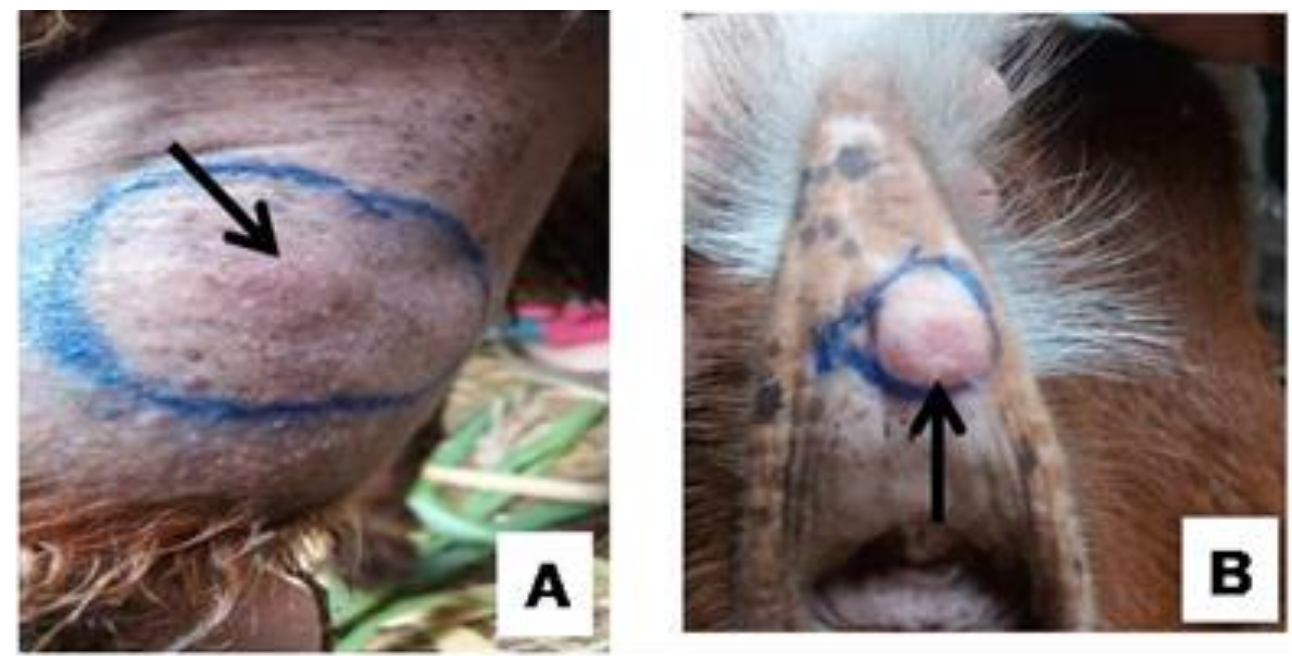

Figure 1: Post- vaccinal reaction in form of slight redness and swelling under the tail of sheep (A) and goat (B) 


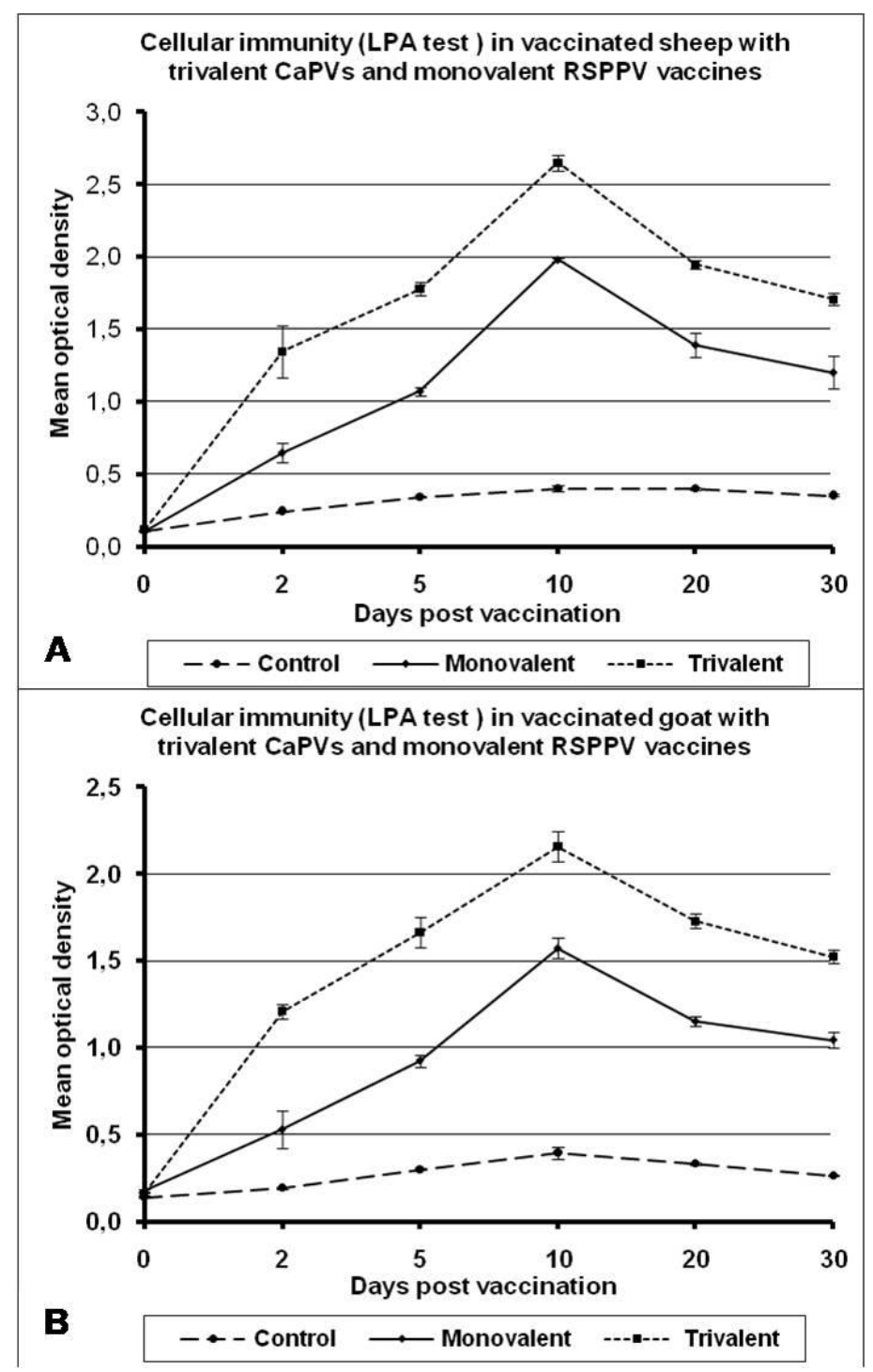

Figure 2: Lymphocyte proliferation index of vaccinated sheep and goats. PBMCs in response to trivalent CaPVs vaccine and monovalent RSPPV vaccine at days 0 (before vaccination), 2, 5, 10, 20 and 30 postVaccination of sheep (A) and goat (B). Protective O.D> 1, values were means \pm SEM 

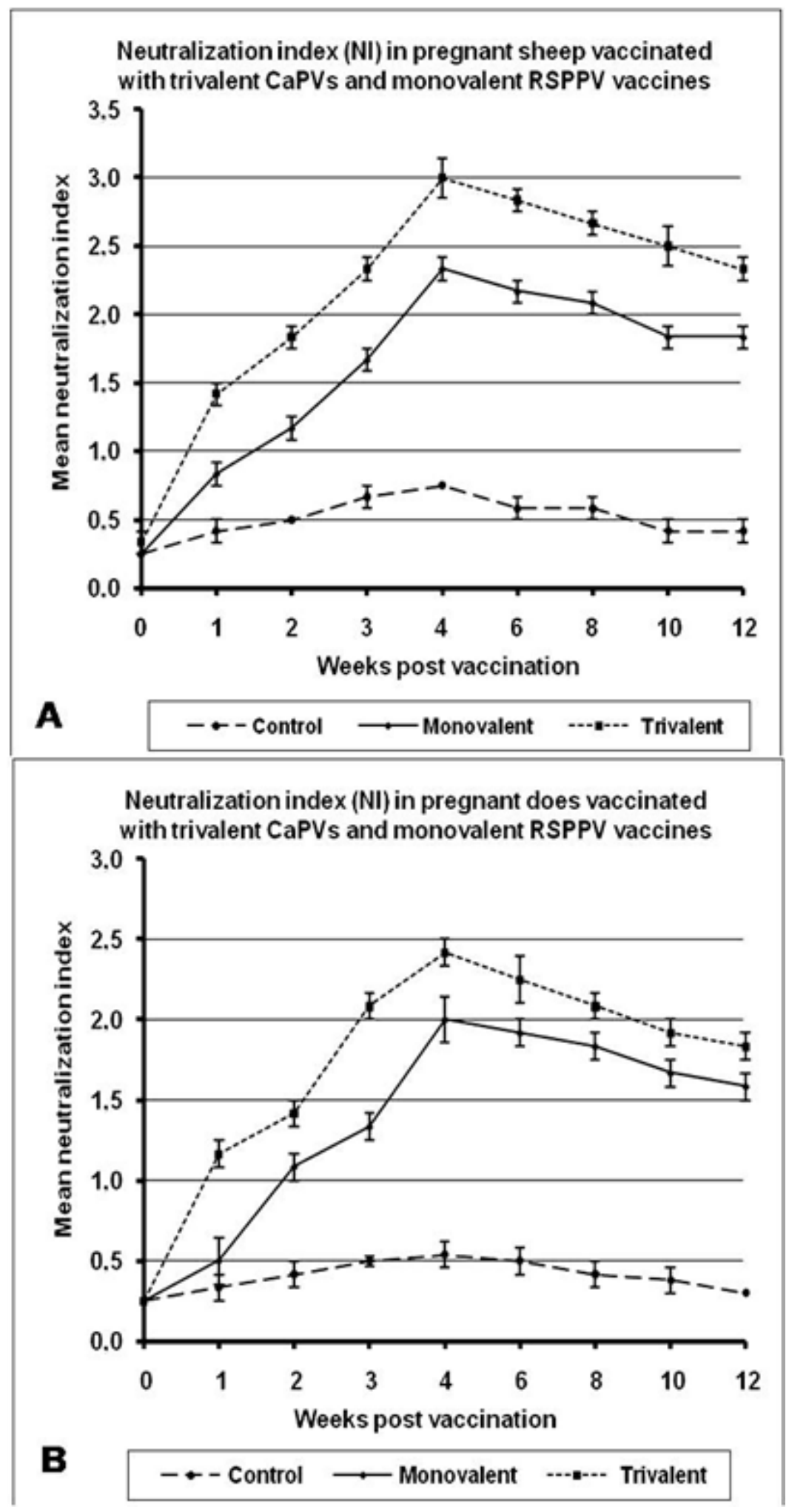

Figure 3: Average NI of vaccinated sheep and goats with trivalent CaPVs vaccine and monovalent RSPPV vaccine from 0 week (Pre-vaccination) till $12 \mathrm{WPV}$. Sheep (A) and goat (B).Values were means \pm SEM. *8 week (time of parturition) 
Table 2: Mean neutralization index of antibodies in serum of lambs and kids. The means with different superscript are statistically difference interaction based on Duncan test

\begin{tabular}{lllll}
\hline \multirow{2}{*}{$\begin{array}{l}\text { Weeks after } \\
\text { birth }\end{array}$} & Lambs & \multicolumn{3}{l}{ Kids } \\
\cline { 2 - 5 } & Trivalent & Monovalent & Trivalent & Monovalent \\
\hline 1 & $2.38 \pm .0 .0161^{\mathrm{ab}}$ & $1.81 \pm .0 .063^{\mathrm{ef}}$ & $2.50 \pm 0.102^{\mathrm{a}}$ & $2.07 \pm 0.063^{\mathrm{cd}}$ \\
2 & $2.25 \pm .0 .102^{\mathrm{ac}}$ & $1.69 \pm .0 .063^{\mathrm{fgh}}$ & $2.19 \pm 0.119^{\mathrm{bcd}}$ & $1.63 \pm 0.072^{\mathrm{fgh}}$ \\
3 & $2.19 \pm .0 .1196^{\mathrm{bcd}}$ & $1.63 \pm .0 .072^{\mathrm{fgh}}$ & $2.06 \pm 0.063^{\mathrm{cd}}$ & $1.62 \pm 0.068^{\mathrm{fgh}}$ \\
4 & $2.00 \pm .0 .102^{\mathrm{de}}$ & $1.63 \pm 0.072^{\mathrm{fgh}}$ & $1.81 \pm 0.063^{\mathrm{ef}}$ & $1.56 \pm 0.063^{\mathrm{ghi}}$ \\
6 & $2.00 \pm .0 .102^{\mathrm{de}}$ & $1.50 \pm 0.102^{\mathrm{hij}}$ & $1.8 \pm 0.068^{\mathrm{ef}}$ & $1.13 \pm 0.072^{\mathrm{lm}}$ \\
10 & $1.81 \pm 0.063^{\mathrm{ef}}$ & $1.31 \pm 0.063^{\mathrm{jkl}}$ & $1.69 \pm 0.063^{\mathrm{fgh}}$ & $1.11 \pm 0.066^{\mathrm{lm}}$ \\
12 & $1.75 \pm 0.001^{\mathrm{fg}}$ & $1.31 \pm 0.063^{\mathrm{jkl}}$ & $1.63 \pm 0.072^{\mathrm{fgh}}$ & $1.06 \pm 0.063^{\mathrm{m}}$ \\
\hline
\end{tabular}

\section{Discussion}

Vaccines have an important role in protection against endemic infectious diseases in Egypt. Vaccination protects the welfare of farm animals and reduces the pain associated with illness, present study was intended to detect the safety of a candidate trivalent CaPVs vaccine in pregnant small ruminants (specific and preferable host) and evaluate the immunity of this vaccine compared with commercial RSPPV vaccine (positive control) as well as the passive immunity in the new-born lambs and kids to determine the most suitable age for the first immunization.

Post-vaccinal reaction in the form of accepted increases in rectal temperature with redness and swelling at the inoculated site are the common characteristic feature of genus CaPVs due to its dermotrophic nature, this reaction was observed exactly in G1 than G2 without statistically significant difference in between $(\mathrm{P}>0.05)$, this indicate initial immunogenic response of the vaccines, similar results were recorded by $(27,28,21)$. Gari et al. (29) said that when the local reactions at inoculation site of vaccine were very low or not observed this indicate that the vaccine viruses was over-attenuated and therefore failed to produce an effective
CMI. The close observation of vaccinated groups revealed that both vaccines were found to be safe without adverse reaction on animal's health according to parameters of vaccine safety recorded by (14).

Protective immunity of genus CaPVs depend on both CMI and the humoral immunity, CMI response considered the predominant way to eliminate the infection against CaPVs. In recent years, the immunological studies focused on CMI role in defense mechanism (30). PBMCs after activation with CaPVs antigens were shown higher lymphocyte proliferation than un-activated PBMCs (31). In the present study, cultured PBMCs of both (trivalent vaccinated group) G1 and G2 (monovalent vaccinated group) were analyzed by using the sensitive XTT substance and were shown high proliferation than G3 (un-vaccinated group) with a significant difference ( $\mathrm{P}$-value $<0.05$ ), lymphocytes proliferation of sheep and goats in G1 were shown higher optical density level than sheep and goats in G2 at all-time points of experiment, these results were in agreement with $(21,22,32)$ who reported that increase of lymphocyte proliferation at $3^{\text {rd }} \mathrm{DPV}$ after CaPVs vaccines strains activation till reached its peak on day $10^{\text {th }}$ day then decreased thereafter. 
The protective immune system against CaPVs infection not only depends on the cellular immunity but also the specific Abs that related to the durability of protection (33). SNT is a reliable and accurate method for specific Abs detection (34). In this study, (trivalent vaccinated group) G1 and (monovalent vaccinated group) $\mathrm{G} 2$ were able to produce Abs in response to $\mathrm{CaPVs}$ vaccine strains with significant difference $(\mathrm{P}$-value<0.05). Protective NI> 1.5 against genus $\mathrm{CaPV}$ s according to (14) reach its peak level at $4^{\text {th }}$ WPV agreement with (28) with increase its level in sheep and goats of G1 than sheep and goats of G2 all weeks of samples collection till end of experiment (12 weeks). Christine et al. (21) evaluated bivalent (RSPPV and Held GTPV) vaccines in cattle and reported that the bivalent vaccine is effective than RSPPV vaccine with a good protective index till 20 weeks (end of experiment) that could be still later. Trivalent $\mathrm{CaPV}$ s vaccine was evaluated in cattle by (22) who recorded that trivalent CaPVs vaccine provide highly protective Abs compared with monovalent RSPPV vaccine with $66 \%$ and $0 \%$ till 9 month post- Vaccination, respectively. Increases level of LPA and SNT in ruminants animals vaccinated with trivalent CaPVs vaccine than monovalent RSPPV vaccine was explained by $(35,36)$ who reported that GTPV vaccine induce a good immunogenic response than SPPV vaccine with high level of lymphocyte proliferation and Abs titer. In the present research, the peak level of O.D in vaccinated sheep and goats appeared at $10^{\text {th }}$ day post-vaccination in comparison with the neutralizing protective Abs that reached its peak at $4^{\text {th }}$ weeks post-vaccination this showed that the immunity against pox disease depend at first days after acquired immunity on $\mathrm{T}$ - lymphocytes.

Immunoglobulin $\mathrm{G}$ ( $\mathrm{IgG})$ is transferred through the colostrums and it's the main Ig responsible for neutralizing viruses through binding pathogenic agents and induces the humoral immune response (37), so in this study we should evaluate the new candidate trivalent CaPVs vaccine in pregnant dams and measure the level of protective immunity compared with monovalent RSPPV vaccine. In the actual study, the peak protective Abs was measured in G4 (lambs and kids of trivalent vaccinated dams) and G5 (lambs and kids of monovalent vaccinated dams) after $1^{\text {st }}$ week after birth these results were agreed with (38) who reported that SPPV and GTPV vaccines were effective in producing hyperimmune colostrum that providing new-born lambs and kids during their first seven days. NI titer of SNT was still protective with a relatively good level till $10^{\text {th }}$ weeks after birth in lambs and kids of G4 (1.75 \pm 0.001 , $1.63 \pm 0.072$, respectively) while at 12 week of experiment the level of NI is slightly decreased under protective NI of lambs and kids $(1.38 \pm 0$. $063,1.25 \pm 0.102$, respectively) so it's advisable to start the vaccination program at 2.5 months after birth before the protective Abs decline with $\mathrm{CaPVs}$ vaccine while lambs and kids from monovalent vaccinated dams (G5) Abs still protective till $\left(6^{\text {th }}, 4^{\text {th }}\right.$ weeks after birth, respec-

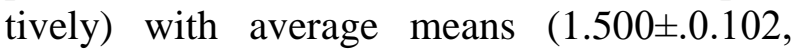
$1.563 \pm 0.063$, respectively). Effective vaccination of young animals at the appropriate time is cost effective practice for eradication of genus CaPVs diseases in Egypt. Little recent researches display the duration of maternal immunity of SPPV vaccine in sheep and goats, according to $(39,40)$ who found that maternal immunity in new-born lambs and Kids from vaccinated dams with SPPV vaccine last for 3 and 2 months respectively but in the present study the data obtained that the pregnant dams vaccinated with RSPPV vaccine provide its newborn lambs and kids with Abs protection last for 45 days and 30 days, respectively in comparison with trivalent $\mathrm{CaPVs}$ vaccine that provided a relatively protective Abs last for 3 months in both lambs and kids. It is unknown whether the low titre of circulating maternal are sufficient to block vaccine responsiveness, so early onset of lambs and kids vaccination with a safe trivalent CaPVs vaccine will provide more efficient protection by inducing both CMI and humeral immunity. The major mention of using trivalent CaPVs can be used for protection cattle against LSDV due to its induction of a long duration of immunity without generalized post-vaccinal reaction $(21,22)$. 


\section{Conclusion}

From this investigation, we concluded that the trivalent CaPVs vaccine gave a good immune response based on both cellular and humoral immunity which represented by the induction of higher level of lymphocytes proliferation and Abs titer respectively, in addition to a high safety degree on pregnant dams and ability to provide relative long protective passive immunity to new-born lambs and kids than the commercial RSPPV vaccine. Trivalent vaccine should be used in vaccination of lambs and kids at 2.5 month of age to avoid the re-occurrence of outbreak. Due to the close antigenic relationship between genus CaPVs strains so we recommended the use of this trivalent vaccine as new candidate in Egypt to control reoccurrence of LSD in cattle with further study to evaluate its efficacy in cattle is also advisable.

\section{Conflict of interest}

The authors declare that they have no conflict of interest.

\section{References}

1. Kitching RP, Taylor WP. Clinical and antigenic relationship between isolates of sheep and goatpoxviruses.Trop Anim Health Prod 1985; 17: 64-74.

2. Babiuk S, Bowden TR, Boyle DB, Wallace DB, Kitching RP. Capripoxviruses: An Emerging Worldwide Threat to Sheep, Goats and Cattle. TransbounEmerg Dis 2008; 55(7):263-72.

3. Buller RM, Arif BM, Black DN, Dumbell KR, Esposito JJ. Virus Taxonomy: Classification and Nomenclature of Viruses. Eighth Report of the International Committee on Taxonomy of Viruses. Elsevier Academic Press, 2005;117-33.

4. Rao TVS, Bandyopadhyay SK. A comprehensive review of Goatpox and Sheeppox and their diagnosis.Anim Health Res Rev 2000; 1: 127-132.

5. Bhanuprakash V, Moorthy ARS, Krishnappa G, SrinivasaGowda RN, Indrani BK. An epidemiological study of sheeppox infection in Karnataka state, India. Revue scientiet technique (Inter Office of Epizo) 2005; 24 (3): 909-20.

6. Abu-Elzein E, Housawi F, Ramadan O. Observations on natural and experimental infection of sheep and goats with a virulent field Capripoxvirus with high affinity to goat. Vet Arhiv 2003; 73(3): 119-31.
7. Iran Veterinary Organization. survey analysis on sheeppox and goatpox in IRAN during 20102014. Pox National CommiteeBultin of Iran Vet Organization, Tehran, Iran 2013.

8. Kitching RP. The control of sheep and goatpox. Revue Scientiet Technique de l'OIE (France). 1986; 5:503-11.

9. Rweyemamu MM, Roeder PL, Taylor WP. Towards the global eradication. In: Barret T, Edn.). Cambridge: Institute of Animal Health, Biology of Animal Infection Series, Academic Press, 2006; 99-322.

10. Bhanuprakash V. Prospects of control and eradication of capripox from the Indian subcontinent: A perspective. Antiviral Res 2011; 91: 22532

11. Kitching RP. Vaccines for lumpyskindisease, sheeppox and goatpox. Develop in biolog. 2003; 114: 161-7.

12. Brenner J, Bellaiche M, Gross E, Elad D, Oved Z, Haimovitz M, Wasserman A, Friedgut O, Stram Y, Bumbarov V, Yadin H. Appearance of skin lesions in cattle populations vaccinated against lumpyskindisease: statutory challenge. Vaccine $\mathbf{J}$ 2009; 27:1500-3.

13. Somasundaram MK. An outbreak of lumpyskindisease in a Holstein dairy herd in Oman: a clinical report. Asian $\mathbf{J}$ of Anim and Vet Advan $2011 ; 6(8): 851-9$

14. OIE (Office International des Epizooties. Sheeppox and goatpoxManual of Diagnostic Tests and Vaccines for Terrestrial Animals, Paris.Chapter 2. $2012 ; 7(14): 1-12$.

15. Gelaye E, Belay A, Ayelet G, Jenberie S, Yami M, Loitsch A, Tuppurainen E, Grabher R, Diallo A, Lamien CE. Capripox disease in Ethiopia: Genetic differences between field isolates and vaccine strain, and implications for vaccination failure. Antiviral Res 2015; 119: 28-35.

16. Salib FA, Osman AH. Incidence of lumpyskindisease among Egyptian cattle in Giza Governorate, Egypt. Vet World. 2011; 4: 162-7.

17. Elhaig MM, Selim A, Mahmoud M.Lumpyskindisease in cattle: Frequency of occurrence in a dairy farm and a preliminary assessment of its possible impact on Egyptian buffaloes. Onderstepoort J of Vet Res 2017; 2219-35.

18. Fatma M Abdallah, Hend M El Damaty, Gamilat F Kotb. Sporadic cases of lumpyskin disease among cattle in Sharkia province, Egypt: Genetic characterization of lumpyskindisease virus isolates and pathological findings. Vet World. 2018; 2231-0916. 
19. Agrawal SK, Soman JP. Assessment of immune efficacy of attenuated live goatpox vaccine against sheeppox and contagious ecthyma.Indian Vet J 1997; 74(12): 1016-18.

20. Christine A Mikhael. Trialsfor preparation of improved bivalent vaccine for sheeppoxand goatpox viruses. PhD Cairo university 2012.

21. Christine A Mikhael, Olfat E. Nakhla,Namaa A. Mohamed. Study on the capability of a dual Capripoxvaccine in protection of cattle against LSD infection. J of vet medicine res 2017; 24 (1): 22433.

22. Aboul-Soud EA, Kafafy MH, El-Suall SA, Zaghloul MA, Christine A Mikhael. Preparation of trivalent vaccine against lumpy skin disease using different capripox viral strain. International J. of Vet. Science and Medicine 2018 (inpress).

23. Reed LJ, Muench H. Simple methods of estimating fifty percent end point .American J. of Hygi 1938; 27:493-7.

24. Ting A, Morris PJ. A technique for lymphocyte preparation from stored heparinized blood. Vox.Sang.1971; 20:561-3.

25. Roehm NW, Rodgers GH, Hatfield SM. An improved colorimetric assay for cell proliferation and viability utilizing the tetrazolium salt XTT. J of immuno methods. 1991; 142:257-65.

26. Berridge MV, Herst PM, Tan AS. Tetrazolium dyes as tools in cell biology: New insights into their cellular reduction. Biotech Annual Rev 2005; 11:127-52.

27. Fakri F, Ghzal F, Daouam S, Elarkam A, Douieb L, Zouheir Y, Tadlaoui K, Fassi-Fihri O. Development and field application of a new combined vaccine against Peste des Petits Ruminants and SheepPox. Trials in Vaccin.2015; 4: 33-7.

28. Zeidan SM, NamaaAM, Hanan MSE, Saad MAA, Olfat EN, Afaf AAW, Abeer AT, El- Dakhly AT. Preliminary study for preparation of combined attenuated vaccine against sheeppox and $P P R$ viruses. Inter. J. of Adva. Res 2016;4: 212-9.

29. Gari G, Abie G, Gizaw D, Wubete A, Kidane M, Asgedom H. Evaluation of the safety, immunogenicity and efficacy of three capripoxvirus vaccine strains against lumpy skin disease virus. Vaccine $\mathrm{J}$ 2015; 33(28):3256-1.
30. Green S, Ennis FA, Mathew A. Long term recall of memory CD8T cells in mice to first and third generation smallpox vaccines. Vaccine J 2011; 29(8):1666-76.

31. Ahmed AM, Mukhtar MM, El Hussein AM, Tageidin AM, Fadol MA. Immune response of sheep vaccinated with Capripox vaccine. Vet. Res 2007; 1(1):12-16.

32. Nermeen G Shafik, Ibrahim MM, Sonia A Rizk, Ali AM. Use of Different Immune Response Assays for Evaluation of Live Attenuated Sheep pox Vaccine as Alternatives to Challenge Test. Global J of Medical Res 2017; 17:2(1)0975-5888.

33. Barmana D, Chatterjee A, Guhaa C, Biswasa U, Sarkarb J, Royc TK, Roya B, Baidyad S. Estimation of post-vaccination antibody titre against goatpox and determination of protective antibody titre. Small Rum Res 2010; 93(2): 76-8.

34. Gelagay A, Nigussu F, Shiferaw J, Gedlu M, Teshale S, Haileleul N. Study on immunogenicity of combined sheep and goatpox and peste des petitis ruminants vaccines in small ruminants in Ethiopia. Afri J of Microbio Res 2012; 6: 7212-7.

35. Norian R, AfzalAhangran N, Varshovi HR, Azadmehr A. Comparative efficacy of two heterologous capripox vaccines to control lumpy skin disease in cattle. Bulg J of Vet Med 2017; 1311-477.

36. Varshovi HR, Norian R, Azadmehr A, AfzalAhangranN.Immune response characteristics of Capripoxvirus vaccines following emergency vaccination of cattle against lumpy skin disease virus. Iranian J of Vet Sci and Tech 9(2) 33-40.

37. Atkinson DE, Boyd RDH,Sibley CP. Placental Transfer. Elsevier, Manchester press, 2000; 2787-846.

38. Burezq HA, Razzaque MA. Effects of immunizing pregnant ewes and does on the humoral immune response of secreted colostrums. J of Anim and Plant Sci 2018; 28 (1): 341-7.

39. Kitching P. Passive protection of sheep against Capripoxvirus. Res in vet sci 1986; 41: 24750 .

40. AbuElzein EME, Housawi F.M.T, Al-Afaleq AI, Ibrahim AO. Protection of Goats, with a Sheeppox Vaccine, Against a Virulent Field Capripoxvirus with High Affinity to Goats.Sci J of King Faisal Univ 2004; 5 (2): 1425. 